\title{
Aa. Vv., L'Habit fait-il le moine?, «Questes. Bulletin des jeunes chercheurs médiévistes», 25
}

\section{Maria Colombo Timelli}

\section{CpenEdition}

\section{Journals}

Édition électronique

URL : http://journals.openedition.org/studifrancesi/1059

DOI : 10.4000/studifrancesi. 1059

ISSN : 2427-5856

Éditeur

Rosenberg \& Sellier

\section{Édition imprimée}

Date de publication : 1 novembre 2014

Pagination : 563

ISSN : 0039-2944

\section{Référence électronique}

Maria Colombo Timelli, «Aa. Vv., L'Habit fait-il le moine?, «Questes. Bulletin des jeunes chercheurs médiévistes», 25 », Studi Francesi [En ligne], 174 (LVIII | III) | 2014, mis en ligne le 01 novembre 2014, consulté le 18 septembre 2020. URL : http://journals.openedition.org/studifrancesi/1059 ; DOI :

https://doi.org/10.4000/studifrancesi.1059

Ce document a été généré automatiquement le 18 septembre 2020.

\section{(c) (†) $\odot$}

Studi Francesi è distribuita con Licenza Creative Commons Attribuzione - Non commerciale - Non opere derivate 4.0 Internazionale. 


\title{
Aa. Vv., L'Habit fait-il le moine?, "Questes. Bulletin des jeunes chercheurs médiévistes», 25
}

\author{
Maria Colombo Timelli
}

\section{RÉFÉRENCE}

L'Habit fait-il le moine?, «Questes. Bulletin des jeunes chercheurs médiévistes», 25, 2013, pp. 133.

1 Ce numéro de «Questes» prend comme point d'appui un proverbe aussi célèbre qu'ancien, pour discuter les valeurs culturelles et identitaires du vêtement dans les siècles médiévaux.

Dans un article dense, FANNY OUDIN discute le système des signes vestimentaires dans la culture médiévale, et réfléchit sur l'emploi de leurs signes verbaux: de nombreux proverbes et locutions sont cités, qui prouvent bien le rapport strict qui s'établit entre expression linguistique et dimension éthique (L'habit fait il le moine? Quelques réflexions autour des proverbes vestimentaires du Moyen Âge, pp. 1-21). En mimant le proverbe mis en exergue, CAMILLE ROUXPETEL se demande Le turban fait-il l'oriental? Sa contribution porte en effet sur deux éléments qui marquent les descriptions des pèlerins dans quelques récits de voyage en latin et en langue vulgaire: le port de la ceinture et du turban en particulier s'avère être un signe discriminant qui renvoie à une altérité orientale (Les chrétiens de la ceinture dans les récits de pèlerinage occidentaux, XIII-XIV siècle, pp. 23-44). Avec ÉLISE BANJENEC, on se déplace à la cour de Bourgogne du $\mathrm{XV}^{\mathrm{e}}$ siècle, où l'ostentation des joyaux et des ornements assume des fonctions symboliques nettes, en donnant à voir la hiérarchie, l'appartenance, ou encore la valorisation de l'individu (Une cour cousue d'or. Les ornements précieux utilisés par le duc Philippe le Bon, pp. 45-64). SIMON GABAY s'interroge sur le problème de l'«impersonnation», à savoir la capacité de l'acteur à se faire passer pour un autre, à «devenir» un autre, dans le théâtre médiéval; il s'arrête 
d'abord sur les définitions de histrio parues avant le XIII ${ }^{\mathrm{e}}$ siècle (Isidore de Séville, Rufin de Bologne, Boèce), pour citer ensuite quelques témoignages beaucoup plus tardifs (à cheval entre $\mathrm{Xv}^{\mathrm{e}}$ et $\mathrm{XvI}^{\mathrm{e}}$ siècle) qui montreraient à ses yeux que ce concept peut s'appliquer au théâtre du Moyen Âge ("Je» est un autre. Note sur la capacité d'impersonnation de l'acteur avant le XIII esiècle, pp. 65-79). MARIE DE RASSE propose une réflexion sur le travestissement féminin 'sexué', volontaire ou non, en région parisienne entre 1350 et 1500: son corpus indique que - malgré les interdits religieux l'attitude sociale demeure relativement pragmatique et tolérante (Travestissement et transvestisme féminin à la fin du Moyen Âge, pp. 81-98). Le personnage de Faux Semblant de Jean de Meun offre à JONATHAN MORTON l'occasion pour discuter longuement la pensée médiévale sur l'hypocrisie, la satire antireligieuse, en rapport avec les déguisements en religieux et en loup (Des loups en peau humaine: Faux Semblant et les appétits animaux dans 'Le Roman de la Rose' de Jean de Meun, pp. 99-119).

3 Ce fascicule se clôt par quelques mots de conclusion de FANNNY OUDIN (pp. 121-124), la reproduction en couleur de cinq enluminures (pp. 125-126) et surtout de précieux Repères bibliographiques (pp. 127-132). 